\title{
Fiscalização do exercício profissional e projeto ético-político
}

\section{Supervision of professional activities and ethical-political project}

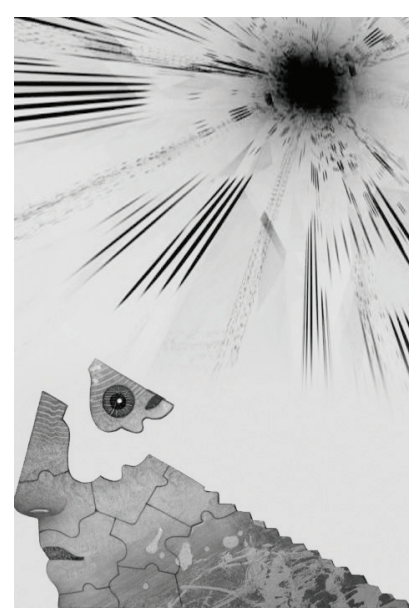

\author{
Josiane Soares Santos* \\ Maria da Conceição Vasconcelos Gonçalves** \\ Débora Rodrigues Santos ${ }^{* * *}$ \\ Elma Santos de Jesus"*** \\ Fábio dos Santos ${ }^{* * * * *}$ \\ Gleide Celma Souza Dórea ${ }^{* * * * * *}$ \\ Raquel de Oliveira Mendes ${ }^{* * * * * *}$
}

Resumo: Este artigo sistematiza parte dos resultados preliminares de um projeto de pesquisa em andamento sobre a temática da fiscalização das profissões pelos conselhos, enfocando especificamente o Conjunto CFESS/Cress com campo empírico situado no Cress $18^{\mathrm{a}}$ Região/SE. Além da análise dos dados, que contribui para entender o

* Assistente social, professora-adjunta e atual coordenadora do curso de graduação Serviço Social da Universidade Federal de Sergipe - Aracaju/SE - Brasil. Doutora em Serviço Social pela Universidade Federal do Rio de Janeiro - UFRJ e vice-presidente regional da ABEPSS na gestão 2009/2010. E-mail: josisoares@hotmail.com.

** Doutora em Serviço Social, professora-adjunta do Departamento de Serviço Social da Universidade Federal de Sergipe — Aracaju/SE - Brasil.

*** Assistente social, professora substituta do Departamento de Serviço Social da Universidade Federal de Sergipe — Aracaju/SE — Brasil.

**** Estudante de Serviço Social da Universidade Federal de Sergipe — Aracaju/SE — Brasil. Bolsista do Programa de Educação Tutorial (PET)/Serviço Social.

****** Estudante de Serviço Social da Universidade Federal de Sergipe - Aracaju/SE — Brasil. Bolsista de pesquisa CNPq/PIBIC/UFS.

****** Estudante de Serviço Social da Universidade Federal de Sergipe — Aracaju/SE — Brasil. Bolsista voluntária de pesquisa.

******** Geógrafa e estudante de Serviço Social da Universidade Federal de Sergipe — Aracaju/SE — Brasil. Bolsista voluntária de pesquisa. 
perfil do exercício profissional a partir dos aspectos que constam nos "relatórios de visita" da fiscalização, traz um debate acerca da concepção de fiscalização do conjunto CFESS/Cress e sua relação com o projeto ético-político profissional.

Palavras-chave: Política Nacional de Fiscalização. Projeto ético-político. Serviço Social.

\begin{abstract}
In this article, part of the preliminary results of a developing research project on the issue of supervision of professional activities by councils is systematized. It focuses on the group CFESS/ Cress with empirical field located in the 18th Cress/SE region. Besides the analysis of the data, which helps to understand the profile of the professional work from the aspects that are in the "visit reports" from the supervision people, it discusses the conception of supervision in the group CFESS/Cress and its relation with the ethical-political project.
\end{abstract}

Keywords: National Supervision Policy. Ethical-political project. Social Services.

\title{
Introdução
}

s reflexões aqui sistematizadas fazem parte dos resultados prelimi-
nares de uma pesquisa em andamento ${ }^{1}$ que tem como objetivo
analisar o exercício profissional do assistente social a partir dos
dados obtidos pela Comissão de Fiscalização do Cress $18^{a}$ Região (estado de Sergipe). A referida pesquisa está vinculada ao do grupo de pesquisa ${ }^{2}$ do Departamento de Serviço Social da Universidade Federal de Sergipe (DSS/ UFS), por meio da linha "trabalho, Serviço Social e formação profissional".

O Serviço Social, por ser regulamentado como uma profissão liberal, traz a necessidade de regulação do seu exercício profissional por meio dos conselhos. Atualmente, além do Conselho Federal de Serviço Social, existem, no Brasil, 25 conselhos regionais e dois seccionais. Ao Conselho Federal compete criar normas para regular e fiscalizar o exercício profissional e aos conselhos regionais cabe a operacionalização dessa fiscalização em cada região. O conjunto CFESS/Cress, ${ }^{3}$ tem como atribuição precípua a fiscalização do exercício pro-

1. A pesquisa mencionada intitula-se "O perfil profissional do assistente social sob a ótica da sua fiscalização pelo Cress $18^{a}$ Região/SE, no período 2002-2008” e é desenvolvida no interior do Programa de Iniciação Científica (Pibic) da Universidade Federal de Sergipe, com financiamento de bolsa pelo CNPq.

2. Trata-se do grupo de pesquisa "Serviço Social, Políticas Públicas e Movimentos Sociais", cadastrado na base do CNPq.

3. Assim é denominada a unidade existente entre as ações do Conselho Federal de Serviço Social (CFESS) e dos Conselhos Regionais de Serviço Social (Cress). 
fissional do assistente social e trabalha de forma democrática e articulada. Desta forma, vale ressaltar que esta atividade (a fiscalização) passou por um processo de ampliação e renovação da sua concepção, pois deixou de ter um caráter meramente disciplinador, adquirindo uma dimensão político-pedagógica que evidencia o compromisso da categoria com a qualidade dos serviços prestados enquanto direitos sociais historicamente conquistados e evidencia compromissos coletivos e públicos com as demandas sociais, sobretudo no que se refere à preocupação com a qualidade dos serviços prestados. A concepção diferenciada de fiscalização adotada no Serviço Social reflete na intervenção profissional no campo das políticas públicas e do controle social também com uma análise diferenciada, pois percebe esses espaços como locus privilegiado para a disputa de projetos societários e a democratização do acesso aos direitos pelas demandas provenientes do trabalho. Essa preocupação torna-se salutar quando considerada a conjuntura de reestruturação do mundo do trabalho a partir de parâmetros neoliberais. Em face de tais questões a Política Nacional de Fiscalização (PNF) é considerada aqui como mais uma das expressões do projeto ético-político do Serviço Social, a exemplo das Diretrizes Curriculares Nacionais para a formação do assistente social.

A metodologia adotada para a realização dessa pesquisa, de cunho exploratório, parte de uma abordagem qualitativa, já tendo sido iniciadas as pesquisas bibliográfica e documental. Em relação à primeira, realizamos um levantamento da produção teórica acerca da fiscalização do exercício profissional. Identificamos que somente no Serviço Social esse tema tem sido objeto de reflexões mais sistemáticas. Portanto, no caso específico da fiscalização, o levantamento baseou-se nas produções do Conselho Federal de Serviço Social. Dentro desse mesmo processo, foi realizado o estudo de outras bibliografias sobre a história da profissão no contexto das transformações societárias, bem como sobre as mudanças ocorridas no mundo do trabalho e da produção capitalista. A pesquisa documental, autorizada pela diretoria do Conselho Regional de Serviço Social $18^{a}$ Região, constituiu-se da análise dos relatórios de visita de fiscalização, realizados pela agente fiscal da Comissão de Fiscalização da entidade. Foram analisados, até o momento, dados de treze relatórios que documentam a totalidade das visitas realizadas no ano de 2008, predominantemente na área da saúde. A seguir serão tratados alguns dos aspectos sistematizados pela pesqui- 
sa em questão, relativos à contextualização teórica do tema e também à análise de parcela dos dados que constam nos relatórios da fiscalização, focalizando a questão das condições de trabalho, da capacitação profissional e da organização/ participação política dos assistentes sociais.

\section{0 processo de renovação do Serviço Social brasileiro: o protagonismo do conjunto CFESS/Cress na constituição do projeto ético-político}

O Serviço Social é uma profissão inserida na divisão social e técnica do trabalho como sendo especializada. Atua no enfrentamento das expressões da "questão social", oriundas da relação capital/trabalho, que refletem o conjunto das desigualdades sociais engendradas pelo processo de produção e exploração capitalista. Na extensa bibliografia sobre a gênese e o desenvolvimento do Serviço Social no Brasil é sabido que o marco de histórico para a efetivação da ruptura entre protoformas e profissão se deu no contexto do capitalismo dos monopólios. ${ }^{4}$ Em meio a esse processo, o crescimento das mobilizações e consolidação das organizações dos trabalhadores, exigia uma resposta do poder estatal.

[...] a profissionalização do Serviço Social não se relaciona decisivamente à "evolução da ajuda", à "racionalização da filantropia", nem à "organização da caridade"; vincula-se à dinâmica da ordem monopólica [...]. Na emergência profissional do Serviço Social, não é este que se constitui para criar um dado espaço na rede sócioocupacional, mas é a existência deste espaço que leva à constituição profissional. [...] não é a continuidade evolutiva das protoformas ao Serviço Social que esclarece a sua profissionalização, e sim a ruptura com elas. (Netto, 2007, p. 69-70)

É no bojo da prestação desses serviços sociais que o Serviço Social emerge, tendo, desde a ditadura varguista, o Estado como o seu principal empregador. Alvo de profunda legitimação por parte das classes dominantes e suas forças políticas presentes no âmbito do Estado, não por acaso esta profissão teve tão precocemente sua primeira regulamentação — através da Lei n. 3.252, de 27

4. Ver a esse respeito especialmente Iamamoto e Carvalho (2007) e Netto (2001). 
de agosto de 1957 —, tendo sido caracterizada, juridicamente, como uma profissão liberal. Este processo impulsionou a criação dos conselhos Federal e regionais da profissão, como representações legais e legítimas perante o Estado, diante da necessidade de normatização e fiscalização do exercício profissional. Nesse mesmo período e entrando na década de 1960, segundo Netto (2007), o mercado de trabalho do assistente social se expande e se consolida, em decorrência das novas manifestações da "questão social", engendradas pelo processo de "industrialização pesada" ocorrido no governo JK e durante a ditadura militar. É nesse último período, por sua vez, que se constitui o processo de renovação do Serviço Social brasileiro. Sobre esse período histórico para a profissão, Netto afirma que

no âmbito das suas natureza e funcionalidade constitutivas, alteram-se muitas demandas práticas a ele colocadas e a sua inserção nas estruturas organizacional-institucionais (donde, pois, a alteração das condições do seu exercício profissional); a reprodução da categoria profissional — a formação dos seus quadros técnicos — viu-se profundamente redimensionada (bem como os padrões da sua organização como categoria); e seus referenciais teórico-culturais e ideológicos sofreram giros sensíveis (assim como as suas autorrepresentações). (2007, p. 115)

Do final da década de 1960 até o início da de 1970, o exercício profissional permanece - nos termos do próprio autor — vinculado às práticas do Serviço Social tradicional, regido pelo empirismo e pela burocratização e orientado pela ética liberal-burguesa, inspirada em uma concepção positivista-funcionalista. O processo de "modernização conservadora" do ciclo ditatorial interfere tanto no exercício quanto na formação profissional do assistente social. O grande salto nacional da industrialização, dado durante o regime militar, intensificou o processo de produção e reprodução da "questão social", provocando suas novas formas de se manifestar na realidade. O Estado brasileiro, como centralizava cada vez mais o seu poder interventivo, teve que intensificar as formas de enfrentamento às novas expressões da "questão social" por meio do investimento também em políticas sociais.

A reforma do Estado, já em fins da década de 1960, redirecionou ainda mais o sentido das políticas setoriais em favor do grande capital. O Estado 
brasileiro mudava a sua estrutura e seu funcionamento organizacional, alterando, por sua vez, a relação dos assistentes sociais com as respectivas instituições empregadoras, com os recursos disponibilizados para execução das políticas sociais, bem como sua relação com outros profissionais no espaço de trabalho e com os próprios usuários dos serviços. Essas novas demandas profissionais passaram a exigir do assistente social novas competências e capacitações, tanto no exercício quanto na sua formação profissional. Conforme afirma Netto (2007, p. 123):

A racionalidade burocrático-administrativa com que a "modernização conservadora" rebateu nos espaços institucionais do exercício profissional passou a requisitar do assistente social uma postura ela mesma, "moderna", no sentido da compatibilização no seu desempenho com as normas, fluxos, rotinas e finalidades dimanantes daquela racionalidade.

Desta forma, as modernas requisições no campo do trabalho causaram uma "erosão" na base humanista do Serviço Social tradicional, provocando uma mudança em seu perfil, que passou a ser permeado por uma nova "racionalidade" nos procedimentos utilizados.

É nesse contexto geral de "renovação" (Netto, 2007) que se dá a inserção do Serviço Social nas instituições de ensino superior, pois até então a formação dos assistentes sociais se dava em escolas confessionais ou agências de formação específica. Em 1976, o curso de Serviço Social já era ofertado em todo país, entre universidades ou faculdades, públicas e privadas. A inserção do Serviço Social nas universidades foi decisiva para consolidar o seu processo de renovação. A relação direta com o centro da produção do conhecimento, incluindo a abertura dos programas de pós-graduação na área, impactou a formação do assistente social com

[...] a instauração do pluralismo teórico, ideológico e político no marco profissional [...]; a crescente diferenciação das concepções profissionais (natureza, funções, objeto, objetivos e práticas do Serviço Social), derivada do recurso a matrizes teórico-metodológicas alternativas [...]; a sintonia da polêmica teórico-metodológica profissional com as discussões em curso no conjunto das ciências sociais, inserindo o Serviço Social [...] como protagonista que tenta cortar com a subal- 
ternidade (intelectual); a constituição de segmentos de vanguarda [...] voltada para investigação e a pesquisa. (Netto, 2007, p. 135-136)

Nos marcos históricos do Serviço Social tradicional, os conselhos Federal e regionais de Serviço Social, não distantes da mesma perspectiva conservadora, apenas exerciam o seu papel de controle, em nome do Estado, sobre os profissionais. Eram conselhos corporativistas, com função meramente burocrática e disciplinadora do exercício profissional (CFESS, 1996). Até então, a legislação profissional era resguardada por princípios neotomistas e positivistas, haja vista os Códigos de Ética de 1947, 1965 e de 1975 (Barroco, 2001).

Foi a partir da inserção do Serviço Social no contexto universitário e do avanço nos debates promovidos pelas entidades da categoria em meio às lutas pelas liberdades civis e políticas, favorecidas pela crise do "milagre econômico" — reflexo da crise mundial capitalista iniciada nos anos 1970 - que emergiu, no seio profissional, a direção de "intenção de ruptura" com o tradicionalismo. ${ }^{5}$ Sob a égide de um novo embasamento teórico-metodológico, de inspiração marxista, do estímulo à pesquisa científica — incluindo projetos de extensão e estágio supervisionado orientados pelos novos referenciais - é que se torna possível vislumbrar o redimensionamento do significado social da profissão e a construção de um novo projeto profissional em oposição ao que estava posto.

Esse processo, de renovação e de ruptura com o conservadorismo, provocou um redirecionamento também das entidades representativas da categoria. Em 1979, o Serviço Social, já sob influência desse processo, vivencia um marco histórico para a profissão, o III Congresso Brasileiro de Assistentes Sociais (CBAS), mais conhecido como o "Congresso da Virada". O evento ficou assim conhecido "pelo seu caráter contestador e de expressão do desejo de transformação da práxis político-profissional do Serviço Social na sociedade brasileira." (CFESS, 1996, p. 175). Nesse momento, as forças políticas progressistas do país, entre elas movimentos sociais e sindicais, partidos políticos, clamavam pela redemocratização. Assim,

5. Não cabe aqui aprofundar esse debate, mas segundo Netto (2007), no processo de renovação constituem-se mais duas vertentes dentro da profissão: a reatualização do conservadorismo e a perspectiva modernizadora. 
sintonizada com as lutas pela democratização da sociedade, parcela da categoria profissional, vinculada ao movimento sindical e às forças mais progressistas, se organiza e disputa as direções dos Conselhos Federal e Regionais, com a perspectiva de adensar e fortalecer esse novo projeto profissional. (CFESS, 2008, p. 163)

Desta forma, os profissionais comprometidos com as lutas democráticas do conjunto da classe trabalhadora passam a disputar o espaço dos conselhos profissionais de Serviço Social, imprimindo-lhes uma nova direção política, articulada com os movimentos sociais e de outras categorias. A partir de 1983, o $\mathrm{CFAS}^{6}$ impulsiona amplos debates no interior da categoria, vislumbrando a reformulação do Código de Ética vigente, datado de 1975. Esse processo vai corroborar na negação do princípio da neutralidade e coadunar na elaboração do Código de Ética do Assistente Social de 1986, superando a perspectiva a-histórica e acrítica do Serviço Social e admitindo um profissional com competência teórica, técnica e política.

A década de 1990, marcada no Brasil pelo processo de reestruturação produtiva do capital, instaura o neoliberalismo como orientação da regulação estatal. Em decorrência disso, inicia-se a "reforma" do Estado, exata e contraditoriamente, no marco da redemocratização e das conquistas sociais asseguradas na Constituição brasileira de 1988. Diante das mudanças ocorridas no mundo do trabalho e no campo dos direitos sociais, o conjunto CFESS/Cress desencadeia debates para impulsionar a reformulação da legislação profissional, como forma de garantir o comprometimento de uma profissão voltada para os princípios da equidade social e da defesa intransigente dos direitos. Desta maneira, é a partir da década de 1990 que o projeto ético-político do Serviço Social ${ }^{7}$ começa a tomar forma, tendo como marco o novo Código de Ética Profissional (1993) e a nova Lei de Regulamentação da profissão (1993), mas sem esquecer que possui suas bases ineliminavelmente ligadas à "intenção de ruptura" anteriormente mencionada, sendo, em relação a ela, uma espécie de "desenvolvimento".

6. O CFAS (Conselho Federal de Assistentes Sociais) passou a chamar-se CFESS (Conselho Federal de Serviço Social) em 1993, com a aprovação da lei de regulamentação atualmente em vigor.

7. Sobre o projeto ético-político profissional já possuímos uma bibliografia relativamente extensa. Referência fundamental, entretanto, para definir os termos deste debate, deve ser feita a Netto (1999). 
O Código de Ética do assistente social de 1993 representa um grande avanço em relação aos códigos anteriores, visto que rompe com a base filosófica tradicional e define a liberdade, a justiça social e a democracia como valores fundamentais na luta por um novo projeto societário.

A democracia é assumida como valor ético central na medida em que constitui o único padrão de organização político-social capaz de assegurar a explicitação daqueles valores. A democracia é concebida aqui como socialização da política, mas também da riqueza socialmente produzida. (CFESS, 1996, p. 174)

A lei de regulamentação da profissão (Lei n. 8.662/93) também é considerada um grande avanço para o Serviço Social. Ela regulamenta o exercício profissional do assistente social e estabelece as competências e as atribuições privativas do mesmo, previstas, respectivamente, nos seus artigos $4^{\circ}$ e $5^{\circ}$. De acordo com Terra (2007), as competências dizem respeito às atividades que podem ser exercidas tanto pelo assistente social, quanto por outros profissionais; já as atribuições privativas são as atividades profissionais exclusivas dos assistentes sociais.

O processo de afirmação dessa profissão com uma formação crítica e comprometida com os valores democráticos e universais de justiça e equidade social foi potencializado pela criação e aprovação das Diretrizes Curriculares para o curso de Serviço Social em 1996. Vale ressaltar que no caso desta última, o processo foi impulsionado pela Associação Brasileira de Ensino e Pesquisa em Serviço Social (Abepss), em articulação com as instituições de ensino, o conjunto CFESS/Cress e a Executiva Nacional de Estudantes de Serviço Social (Enesso).

No processo de construção do projeto ético-político do Serviço Social ganham relevância as entidades representativas dos assistentes sociais, especialmente o conjunto CFESS/Cress, o qual, em sintonia com o avanço teórico-político vivenciado pelo Serviço Social, também passou por um processo de renovação, por meio da superação de suas características iniciais pautadas no corporativismo e no burocratismo. Assim, houve uma ampliação das atribuições assumidas pelo conjunto CFESS/Cress, pois, a partir da fiscalização do exercício profissional, constituída como sua função precípua, passou a investir na 
qualificação teórico-política dos profissionais, na defesa das políticas públicas e na preocupação com a qualidade dos serviços prestados aos usuários. As propostas e ações das referidas entidades passaram a ser pautadas pelo aprimoramento dos instrumentos normativos necessários à regulamentação e à fiscalização do exercício profissional; pelo investimento na participação nos fóruns de discussão, formulação e controle social das políticas públicas, além da articulação com os movimentos sociais que lutam pela superação das desigualdades sociais e a efetivação de direitos, conforme trataremos a seguir.

\section{Política Nacional de Fiscalização (PNF) como estratégia de enfrentamento aos desafios contemporâneos e defesa da profissão}

Em consonância com o processo de renovação vivenciado pelo Serviço Social, suas entidades representativas desencadeiam uma reestruturação de suas ações objetivando sintonizá-las com o novo direcionamento presente em suas gestões:

É na década de 1980 que o conjunto CFESS/Cress inicia o processo de organização do serviço público de fiscalização do exercício profissional com adoção e aprimoramento de um sistema de inscrição e cadastro; instituição das Comissões de Orientação e Fiscalização; estruturação da fiscalização dos espaços ocupacionais; mapeamento de espaços de trabalho; profissionalização pela contratação de agentes fiscais, e unificação de procedimentos. (Silveira, 2007, p. 11)

O conjunto dessas modificações incidiu, inclusive, na estrutura das entidades, que passou a funcionar de modo colegiado, por meio de comissões, " "que [aglutinam] frentes de luta a partir das temáticas atinentes às políticas sociais, bem como aquelas vinculadas à dinâmica da fiscalização do exercício profissional" (CFESS, 1996, p. 179). Vale destacar ainda o caráter democrático do conjunto CFESS/Cress, visto que as deliberações são frutos de debates empre-

8. O Cress/18 Região possui as seguintes comissões: Comissão de Ética, de Comunicação, Políticas Públicas, Formação Profissional e Orientação e Fiscalização. 
endidos pela categoria em encontros e assembleias, a exemplo do valor da anuidade (estabelecido em assembleia, em suas respectivas jurisdições) assim como o processo de eleição direta para as diretorias regionais e federal. ${ }^{9}$

No bojo desse processo, a fiscalização do exercício profissional do assistente social também passou por um processo de ampliação. Essa ampliação está consolidada na Política Nacional de Fiscalização (PNF) que foi elaborada em 1999, fruto de um processo histórico de organização do conjunto CFESS/Cress, afirmando, assim, a centralidade que a fiscalização tem nas ações do conjunto. A partir de então passa a ser orientada pelas seguintes dimensões:

I - Dimensão afirmativa de princípios e compromissos conquistados - expressa a concretização de estratégias para o fortalecimento do projeto ético-político profissional e da organização política da categoria em defesa dos direitos, das políticas públicas e da democracia e, consequentemente, a luta por condições condignas e qualidade dos serviços profissionais prestados;

II - Dimensão político-pedagógica - compreende a adoção de procedimentos técnico-políticos de orientação e politização dos assistentes sociais, usuários, instituições e sociedade em geral, acerca dos princípios e compromissos éticopolíticos do Serviço Social, na perspectiva da prevenção contra a violação da legislação profissional;

III - Dimensão normativa e disciplinadora — abrange ações que possibilitem, a partir da aproximação das particularidades socioinstitucionais, instituir bases e parâmetros normativo-jurídicos reguladores do exercício profissional, coibindo, apurando e aplicando penalidades previstas no Código de Ética Profissional, em situações que indiquem violação da legislação profissional. (CFESS, 2007, p. 49-51)

Desta forma, a PNF traz, por meio da dimensão político-pedagógica, a afirmação do compromisso da categoria com o constante aprimoramento intelectual dos profissionais, na perspectiva de orientação quanto aos princípios éticos e políticos da profissão, tendo assim um caráter preventivo e indo além da dimensão normativo-reguladora. Destaca-se também a dimensão afirmativa

9. Cabe enfatizar que a eleição direta da diretoria do Conselho Federal não ocorre em nenhum outro conselho profissional (Terra, 2007). 
de princípios que expressam o compromisso com as lutas mais gerais dos trabalhadores, com a qualidade dos serviços prestados à população usuária e, portanto, com a defesa e o fortalecimento do projeto ético-político profissional do Serviço Social.

Desta maneira, a partir das referidas dimensões, percebe-se que a concepção de fiscalização assumida na PNF supera a perspectiva corporativa da organização política quando investe na defesa das políticas públicas e na preocupação com a qualidade dos serviços prestados à população, o que, por sua vez, impacta as condições e relações de trabalho em que se inserem os assistentes sociais. Esta relação pode ser ilustrada, de acordo com o CFESS (1996, p.178179), conforme abaixo:

[...] nós, militantes dos conselhos de fiscalização, compreendemos que a participação nos fóruns de discussão, formulação e controle social das políticas públicas constitui hoje uma estratégia fundamental. Trata-se de uma perspectiva de investimento e reforço nos espaços propositivos e reivindicatórios delineados na pauta de defesa da cidadania. [...] São necessidades profissionais, assim, que dizem respeito ao acesso às condições de trabalho condignas e à garantia de qualidade dos serviços prestados à população. É sabido ainda que a ação profissional do assistente social possui seu locus prioritário, posto pela divisão sociotécnica do trabalho, no planejamento e na execução de políticas sociais [...].

Ainda como parte dessa preocupação a PNF contempla a qualificação teórico-política dos profissionais e o seu processo de participação e organização política como pré-requisitos fundamentais ao alcance do objetivo supracitado. Esses pressupostos fazem da fiscalização, no interior do conjunto CFESS/Cress, um instrumento essencial na ampliação de suas funções que, na atualidade, adquirem uma explícita tonalidade ídeopolítica sem descartar as dimensões normativas próprias a essas entidades.

A operacionalização da fiscalização do exercício profissional do assistente social é competência dos Cress's em suas respectivas regiões. Em cada um deles existe uma Comissão de Orientação e Fiscalização (Cofi) que deverá de acordo com a Resolução CFESS n. 512, de 2007, art. $6^{\circ}$, ser composta por no mínimo três membros: 
I. Um conselheiro, a quem caberá a coordenação;

II. Agentes fiscais concursados;

III. Assistentes sociais inscritos no Cress, em pleno gozo de seus direitos, a convite da direção do CRESS.

O agente fiscal é o membro da Cofi que, preferencialmente, ${ }^{10}$ realiza as visitas de fiscalização às instituições, tendo como instrumento o relatório de fiscalização. Este passou por uma reformulação recente junto com alguns outros aspectos da PNF. Tais reformulações ocorreram em 2007, fruto de debates empreendidos com toda a categoria profissional, tendo em vista "o aprimoramento dos procedimentos e a sedimentação dos avanços obtidos" (CFESS, 2007, p. 49). Desse modo, a resolução CFESS n. 512/2007, ao mencionar as competências da Cofi, estabelece que os relatórios de visita de fiscalização devem ser objeto de discussão e avaliação por parte de seus membros. Entende-se que será a partir das informações obtidas nos relatórios que surgirão as demandas, não somente para a Cofi, ${ }^{11}$ mas, também, para outras comissões existentes no âmbito da entidade.

É importante destacar que a ampliação da concepção de fiscalização concretizada na PNF, assim como a reformulação dos instrumentos que a operacionalizam, é fruto da necessidade da defesa da profissão frente ao contexto atual, pautado no neoliberalismo, que, de acordo com Silveira (2007), vem interferindo diretamente na formação e no exercício profissional do assistente social, trazendo como tendência a desregulamentação da profissão e a redefinição do perfil da categoria.

O neoliberalismo consolida-se, no Brasil, a partir da década de 1990 com a abertura da economia brasileira ao mercado internacional, demarcando um contexto em que o Estado cada vez mais se desresponsabiliza pela "questão social", em que o mercado surge como regulador da vida social, onde as con-

10. De acordo com a Resolução CFESS n. 512/2007, todos os membros da Cofi podem realizar visitas de fiscalização.

11. Terra enfatiza que as comissões de fiscalização têm que estar sempre assessoradas juridicamente, no sentido de ser orientadas sobre os procedimentos cabíveis e sobre as ações sequenciais em cada situação apresentada (Terra, 2007, p. 29). 
dições e relações de trabalho estão cada vez mais precarizadas e os trabalhadores estão perdendo direitos historicamente conquistados. Tal quadro tem como característica uma forte investida na intensificação da exploração do trabalho, principalmente por meio do surgimento de ocupações precarizadas. Deste modo, os profissionais de Serviço Social também vêm sendo consideravelmente impactados por esses fenômenos, que devem ser tomados com centralidade na análise das dificuldades que se avolumam no âmbito do trabalho profissional, dada a sua condição de assalariamento. Com isso, nota-se a importância de aprofundar os princípios preconizados no projeto ético-político profissional e, nesse sentido, urge articular possibilidades de enfrentamento dessa conjuntura. É justamente sob essa perspectiva que emerge, no interior da profissão, a Política Nacional de Fiscalização. No que se refere a esse debate, é necessário elencar a importância dos instrumentos normativos para regular e fiscalizar o exercício profissional nesse momento em que é colocada em xeque a hegemonia conquistada profissionalmente dentro de uma perspectiva crítica e de transformação social. ${ }^{12}$

As profundas transformações econômicas, políticas e sociais em curso modificam de forma substancial a "questão social". Historicamente considerada "matéria" do Serviço Social, apesar de ter sua gênese nas relações sociais capitalistas, apresenta-se na cena contemporânea "com novas roupagens, novas expressões em decorrência dos processos históricos que a redimensionam na atualidade, aprofundando suas contradições" (Iamamoto, 2002, p. 8). As políticas sociais, como resposta articulada do capitalismo monopolista a tais expressões, têm sido tratadas a partir de uma lógica seletiva e fragmentária, longe dos padrões de universalidade, negando profundamente os compromissos assumidos pela profissão em seu projeto ético-político. Isso interfere diretamente na dinâmica do trabalho do assistente social, pois reformula demandas, redimensiona os espaços sócio-ocupacionais e impõe novas competências a esse profissional, o que torna ainda mais difícil estabelecer, no âmbito da fiscalização, o que seja "área", "matéria" e "unidade" de Serviço Social, conforme designa a lei de regulamentação em vigor.

12. Sobre esse debate, ver Braz, 2007. 
Uma pesquisa realizada pelo CFESS $7^{\mathrm{a}}$ Região com assistentes sociais que trabalham em empresas (apud Iamamoto, 2002) demonstrou que, na maioria delas, o Serviço Social não ocupa lugar específico na estrutura organizacional, pois os profissionais passam a atuar em projetos mais amplos, de caráter interdisciplinar, executando funções que muitas vezes não são por eles reconhecidas como atribuições privativas. Assim, "é comum os profissionais se identificarem com os cargos nomeados pelas organizações [...], confundindo cargo ou função com profissão" (Iamamoto, 2002, p. 40).

O grande desafio para o Serviço Social é, diante de um contexto tão regressivo, conseguir concretizar seu projeto ético-político comprometido com a garantia dos direitos sociais dos trabalhadores, com a defesa de políticas sociais universais, com a luta por condições de trabalho adequadas para o exercício profissional e, consequentemente, com a qualidade dos serviços prestados à população usuária.

Silveira (2007) enfatiza, na mesma direção, que o momento é também de resistência das entidades representativas da profissão, especialmente do conjunto CFESS/Cress, sustentadas nos avanços teóricos e ético-políticos construídos coletivamente. Desta maneira,

a fiscalização do exercício profissional, como função precípua do conjunto CFESS/ Cress, deve ser implementada cotidianamente em sintonia com o projeto profissional construído democraticamente pela categoria profissional e requer o envolvimento nas lutas sociais para fortalecer a organização política da classe trabalhadora e contribuir para o enfrentamento das ofensivas conservadoras que cotidianamente impõe desafios à nossa intervenção profissional, política e à consolidação do projeto ético-político profissional. (CFESS, 2008, p. 167-168)

Conclui-se, então, que a atual conjuntura, marcada pela ascensão do projeto neoliberal, demonstra a necessidade de potencialização da Política Nacional de Fiscalização, visto que esta se constitui como um instrumento de consolidação do projeto ético-político profissional na defesa do Serviço Social.

Situada a PNF em sua gênese e desafios contemporâneos, seguimos analisando os dados do perfil profissional dos assistentes sociais em Sergipe. Trazemos, neste momento, reflexões em torno de suas condições/relações de tra- 
balho, capacitação e participação/organização política, tomando por referência os pressupostos e eixos da PNF.

\section{Alguns dados da fiscalização do trabalho do assistente social em Sergipe}

Dos profissionais fiscalizados no ano de 2008, 69,2\% trabalham na área da saúde, 15,4\% estão inseridos na área da assistência social, e 7,7\% estão atuando em empresas. Outros 7,7\% estão estão inseridos em instituições que prestam serviços relacionados a mais de uma área de política social. Esse dado apresenta relações entre as áreas de educação e saúde e entre as áreas de educação, empresa, saúde, provenientes do conjunto de instituições do chamado "Sistema S", que também foi visitado pela fiscalização no ano referido.

$\mathrm{O}$ fato de a maioria dos profissionais estar inserida na área de saúde revela um dado frequente nas pesquisas já realizadas sobre o mercado de trabalho dos assistentes sociais. Porém, neste caso, o índice elevado decorre, possivelmente, do fato de que, no ano de 2008, a Cofi priorizou esta área na atividade de fiscalização. Esse é um procedimento comum entre os conselhos regionais em face do grande número de instituições e profissionais a serem visitados pela fiscalização, e do pouco número de agentes fiscais e membros das Cofi's envolvidos nessa atividade. É importante aqui ratificar que no Cress/SE existe apenas uma agente fiscal, sendo a Cofi composta, além desta, por um assistente social da base e duas conselheiras da diretoria. Segundo dados dos relatórios de visita da fiscalização de 2008, a maioria dos assistentes sociais $(46,2 \%)$ está inserida em instituições de natureza pública municipal.

No que concerne à posição do Serviço Social no organograma das instituições, $61,5 \%$ dos profissionais confirmaram a existência de um setor específico de Serviço Social. Esse dado revela, pois, um reconhecimento das competências do trabalho profissional ao longo dos anos e confirma uma tendência em Aracaju/SE, se comparado à pesquisa sobre o mercado de trabalho profissional no município, realizada entre 2005 e 2006 (Aranha, 2005), que aponta, em média, que 67,5\% das instituições (públicas, privadas e do terceiro setor) possuem um setor específico de Serviço Social. Essa tendência contraria, no 
entanto, outras pesquisas, que sinalizam como característica do mercado de trabalho impactado pela reestruturação produtiva a "diluição" de setores específicos vinculados às profissões, substituindo-os por uma estruturação organizacional vinculada aos cargos ou funções. É o caso, por exemplo, da pesquisa sobre mercado de trabalho nas empresas realizada no Rio de Janeiro (apud Iamamoto, 2002) anteriormente mencionada.

Os relatórios questionam se os profissionais possuem ou não cursos de pós-graduação. Dos profissionais visitados no ano de 2008, 76,9\% possuem pós-graduação, a maioria correspondendo à especialização. Os dados da pesquisa de Santos (2006) e Jesus (2006) sobre o exercício profissional em Sergipe revelam que $60 \%$ possuem curso de pós-graduação. Os dados nacionais indicam uma porcentagem, no Nordeste, de $38,3 \%$, e no país, de $36,2 \%$, para aqueles que possuem especialização (CFESS, 2005). Nesse aspecto, constata-se que os profissionais de Sergipe visitados pela fiscalização em 2008, em sua maioria da área de saúde, têm investido mais em estudos posteriores à graduação, numa comparação com os dados das pesquisas locais e nacional mencionadas. Entretanto, verifica-se que há uma sobreposição da pós-graduação latu sensu em detrimento da stricto sensu. A insuficiência de profissionais mestres e doutores, na medida em que contribui para o aumento do número de professores apenas graduados nas instituições de ensino superior de Serviço Social, tende a comprometer a qualidade da formação profissional. Isso se reflete no exercício profissional, podendo contribuir, juntamente com outros fatores, para a reprodução de uma série de entraves à garantia da implementação do projeto ético-político na academia, na intervenção profissional, nas entidades organizativas da categoria, entre outros espaços. A esse respeito, é pertinente mencionar que o curso de Serviço Social, transferido para a Universidade Federal de Sergipe desde 1968, ainda não conseguiu implantar uma pós-graduação stricto sensu. Este pode ser um dos fatores que dificulta o acesso a esse nível da pós-graduação, posto que a condição feminina da maior parte dos profissionais (Jesus, 2006; Santos, 2005; Cfess, 2005) dificulta que saiam do estado para cursar esse tipo de pós.

Ainda quanto à pós-graduação as justificativas daqueles que não possuem essa titulação residem basicamente de falta de oportunidade $(50,0 \%)$, ou de 
considerarem que não era necessário por terem terminado a graduação há pouco tempo (50\%). Tem-se, em consonância com este panorama, a necessidade de ampliação da oferta de cursos de nível superior nas duas modalidades, latu e stricto sensu, assim como desenvolver um trabalho político-pedagógico de sensibilização dos profissionais no que se refere à necessidade da formação continuada.

Em relação ao número de assistentes sociais existentes nas instituições visitadas pela fiscalização em 2008, a maioria $(53,8 \%)$ registra que existe apenas um profissional atuando; $30,8 \%$ possuem dois assistentes sociais, e 15,4\% possuem três assistentes sociais no quadro de funcionários. Esses dados confirmam, em comparação com a pesquisa sobre o mercado de trabalho dos assistentes sociais em Aracaju/SE, a tendência de cada instituição manter em seu quadro de pessoal apenas um profissional da área de Serviço Social. Ademais, revela ainda uma contradição: existem setores específicos de Serviço Social funcionando, em sua maioria, com apenas um assistente social o que pode ser expressão da reforma do Estado, sob orientação neoliberal, nas instituições de natureza pública municipal, principalmente pela ausência de concursos públicos. Essa última inferência é reforçada pelos dados presentes em Jesus (2006) na medida em que constatam a precarização dos vínculos dos assistentes sociais do setor público municipal em Aracaju, registrada com o percentual de 60\% desses profissionais tendo ingressado nas instituições por meio de indicação ou convite, e apenas $11,4 \%$ por meio de concurso público. A carga horária semanal de trabalho dos assistentes sociais visitados é, na sua maioria $(46,2 \%)$ de quarenta horas; 38,5\% trabalham trinta horas e 15,4\% trabalham mais de quarenta horas. Esses resultados coincidem com os obtidos na pesquisa nacional do CFESS sobre o perfil profissional (2005) que demonstrou que mais da metade $(50,7 \%)$ dos assistentes sociais têm uma carga horária de trabalho de quarenta horas semanais.

No que diz respeito à referência salarial (Gráfico 1), apenas um profissional deixou de responder a esse questionamento. Entre os demais, a grande maioria (49,9\%) admite receber entre $\mathrm{R} \$ 1.250,00$ e $\mathrm{R} \$ 1.500,00 ; 25 \%$ recebem entre $\mathrm{R} \$ 3.000,00$ e $\mathrm{R} \$ 3.500,00 ; 16,7 \%$ têm uma remuneração que varia entre $\mathrm{R} \$ 1.800,00$ e $\mathrm{R} \$ 2.500,00 ; 8,4 \%$ recebem um salário inferior a $\mathrm{R} \$ 1.000,00$. 


\section{Gráfico 1}

Referência Salarial

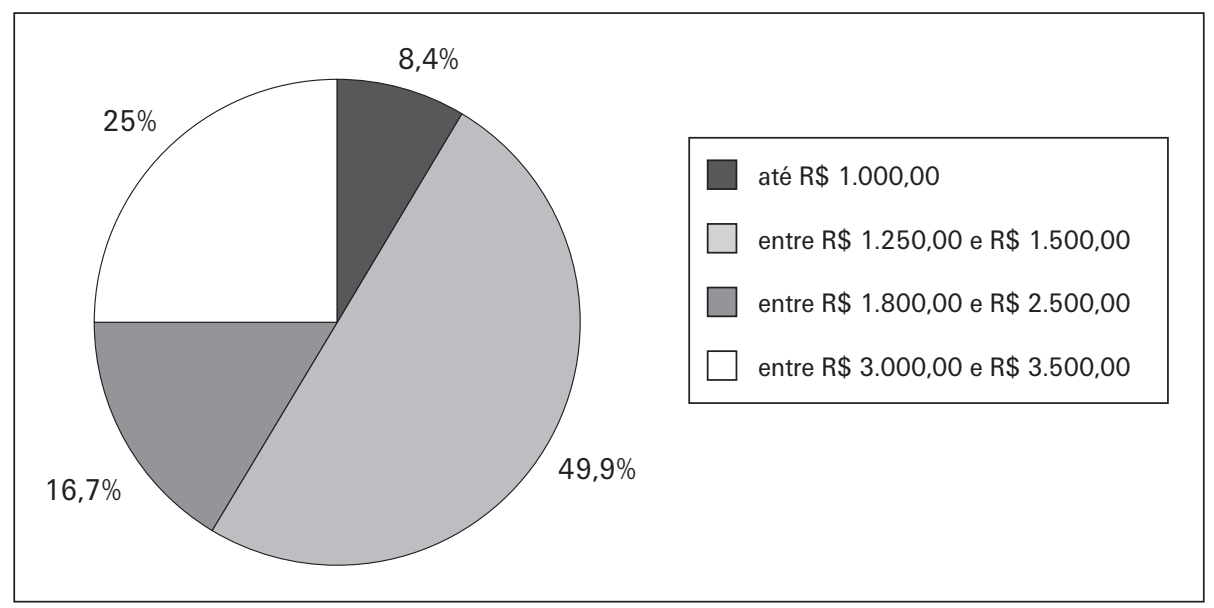

Se fizermos uma análise articulada desses dados com os apresentados anteriormente, perceberemos que a remuneração desses assistentes sociais não condiz com a referência salarial prevista na tabela de honorários do CFESS, disposta na Resolução n. 467/2005. Levando em conta que a maioria dos profissionais trabalha quarenta horas semanais, os mesmos deveriam receber, no mínimo, o equivalente a $\mathrm{R} \$ 2.600,00$. Esse cálculo tem por base o valor da hora de trabalho para graduados em Serviço Social, que equivale a $\mathrm{R} \$ 65,00$. Considerando que o perfil dos profissionais visitados é, na maioria, de especialistas (76,9\%), o cálculo eleva o patamar salarial para $R \$ 2.920,00$, pois é calculado com base no valor de $\mathrm{R} \$ 73,00$ por hora de trabalho. Evidencia-se, portanto, um quadro de precarização das condições e relações de trabalho expresso pelo baixo nível dos salários percebidos quando pensados sob a ótica da demanda de trabalho relacionada à quantidade de profissionais que tende a indicar uma sobrecarga de atividades na dinâmica dessas instituições. Vale chamar a atenção dessa situação como parte integrante de um processo mais amplo em que estão inseridos os trabalhadores assalariados no contexto contemporâneo da crise capitalista recente.

No que se refere às principais ações dos assistentes sociais, o relatório de visita da fiscalização nomeia algumas das competências previstas no artigo $4^{\circ}$ 
da Lei de Regulamentação da profissão. Os resultados demonstram que a ação mais presente entre as atividades profissionais é o atendimento direto à população usuária, feito por 85,7\% dos profissionais (Tabela 1). Assim, esses resultados reafirmam o assistente social enquanto profissional que trabalha diretamente com a população usuária, ou, nos termos de Netto (2001), como "executor terminal de políticas sociais". A essa tendência devem se somar ainda $14,3 \%$ dos profissionais visitados pela fiscalização que trabalham com a administração de benefícios. Esses dados são compatíveis com a pesquisa realizada no setor público de Aracaju, que evidencia um percentual de 84,3\% dos profissionais que se inserem nesse perfil, realizando atividades como "orientação quanto aos direitos e benefícios sociais" (Jesus, 2006, p. 22). Entretanto, como afirma Iamamoto (2002, p. 37),

embora este ainda seja o perfil predominante, não é mais exclusivo, sendo abertas outras possibilidades. O processo de descentralização das políticas sociais públicas — com ênfase na sua municipalização — requer dos assistentes sociais, como de outros profissionais, novas funções e competências. Estão sendo requisitados e devem dispor de competências para atuar na esfera da formulação e avaliação de políticas, assim como do planejamento e gestão.

Tabela 1 - Principais ações

\begin{tabular}{|l|c|c|c|c|c|}
\hline Ações & $\begin{array}{c}\text { Realiza } \\
(\%)\end{array}$ & Frequência & $\begin{array}{c}\text { Não realiza } \\
(\%)\end{array}$ & Frequência & $\begin{array}{c}\text { Total da } \\
\text { frequência }\end{array}$ \\
\hline $\begin{array}{l}\text { Atendimento direto à população } \\
\text { usuária }\end{array}$ & 85,7 & 11 & 14,3 & 2 & 13 \\
\hline $\begin{array}{l}\text { Assessoria e apoio a movimentos } \\
\text { sociais e populares }\end{array}$ & 42,9 & 6 & 57,1 & 7 & 13 \\
\hline $\begin{array}{l}\text { Planejamento e coordenação de } \\
\text { políticas e programas sociais }\end{array}$ & 21,4 & 3 & 78,6 & 10 & 13 \\
\hline $\begin{array}{l}\text { Assessoria e consultoria em } \\
\text { políticas sociais }\end{array}$ & 14,3 & 2 & 85,7 & 11 & 13 \\
\hline Administração de benefícios & 14,3 & 2 & 85,7 & 11 & 13 \\
\hline
\end{tabular}


Além do atendimento direto e da administração de benefícios, os dados da fiscalização atestam que 42,9\% dos profissionais realizam assessoria e apoio a movimentos sociais e populares. Vale destacar que, em relação à pesquisa de Jesus (2005) e Santos (2005/2006), esta atividade obteve uma frequência média de $86 \%$ nos três setores (público, privado e ONGs) em Aracaju/SE. Como já referido, estando os profissionais visitados vinculados predominantemente ao setor público municipal na área de saúde, este fato parece indicar uma presença acentuada do trabalho dos assistentes sociais no reforço à dinânica do controle social. Essa reflexão tem por base as indicações de Iamamoto (2002), que relacionam o espaço de potencialização dos conselhos ao fortalecimento das entidades e organizações populares. Os dados são compatíveis com a afirmação dela de que a atividade profissional tradicionalmente referenciada como "trabalho de base, educação e mobilização popular", apesar da mudança da nomenclatura - assessoria e consultoria a movimentos sociais - , mantém-se como demanda no exercício profissional, muito embora tenha perdido espaço no campo da formação acadêmica e do debate teórico.

Devemos considerar ainda que, embora com um percentual minoritário $(14,3 \%)$, a assessoria e consultoria em políticas sociais também foi mencionada entre as ações realizadas pelos profissionais visitados. Percebendo a interface das duas ações, destacamos o seu caráter de assessoria, bem como o "objeto" sob o qual as mesmas são exercidas, isto é, as políticas sociais. Consideramos que o acúmulo da produção teórica do Serviço Social sobre a temática das políticas sociais, pode estar contribuindo para que essa demanda se apresente aos profissionais em atividades, como, por exemplo, a formação e capacitação de conselheiros no âmbito das políticas e direitos sociais. Outro dado que reforça esta análise é a sua interface com a participação/organização política dos assistentes sociais. Um número significativo entre os profissionais visitados pela fiscalização em Sergipe no ano de 2008 (75\%) se manifestou engajado no acompanhamento das discussões das entidades do Serviço Social no tocante à política pública. Este mesmo percentual (75\% dos profissionais) mostrou-se engajado nas discussões de políticas públicas na sua instituição de trabalho, bem como tem participado de algum tipo de conselho.

O debate sobre as políticas públicas fomenta a análise dos dados que se referem ao controle social e ao debate, a ele associado, da descentralização 
política preconizada tanto pelo neoliberalismo quanto pelos movimentos sociais e pela Constituição Federal de 1988 nos seus artigos 198 e 204. Sabemos da diferença existente na abordagem de cada um desses segmentos (Estado neoliberal e movimentos sociais). O ideário neoliberal entende os mecanismos dos conselhos como tentativa de transferir as responsabilidades do Estado para a sociedade civil. Já os movimentos sociais defendem a descentralização enquanto mecanismo que viabiliza a sua participação no planejamento, implementação e avaliação das políticas públicas. Assim, a descentralização política representa uma possibilidade de disputa de projetos societários e, nesse sentido, pode ser revestida para beneficiar segmentos da sociedade civil provenientes de demandas do trabalho. Ratificando o debate da descentralização na última direção citada, Raichelis (2007, p. 79) considera a relação entre publicização e esfera pública entendendo a primeira "como um movimento de sujeitos sociais que requer um locus para consolidar-se" e a segunda como locus de consolidação daquela. Consideram-se, assim, esses espaços (os conselhos) enquanto palcos de disputa entre diferentes projetos societários representando possibilidades de construção da democracia nas políticas sociais, ao passo que permite o envolvimento da sociedade civil na sua definição e implementação.

Esta discussão torna-se relevante para disputa de diferentes projetos societários no interior do Serviço Social. Isso se dá na medida em que a inserção de setores organizados da sociedade e de profissionais comprometidos com o projeto ético-político profissional do Serviço Social nesses espaços pode ser favorável para formulação, gestão e controle das políticas públicas voltadas para a classe trabalhadora. Partindo dessa perspectiva, o conjunto CFESS/Cress construiu frentes de trabalho articuladas à elaboração da política nacional de fiscalização profissional (PNF), entendendo os espaços de controle social das políticas públicas enquanto lugar que pode propiciar a melhoria na qualidade dos serviços prestados à população, além de oportunizar à fiscalização o levantamento das condições de trabalho dos assistentes sociais diante dos desafios colocados pelo contexto neoliberal.

Ainda referindo-nos aos dados pertinentes aos mecanismos de controle social e suas relações com a profissão, notou-se, em Sergipe, a predominância de profissionais nos conselhos locais de Saúde (60\%), seguidos do Conselho 
Municipal de Assistência Social e do Conselho Municipal de Direitos da Criança e Adolescente, que ficaram tecnicamente empatados (10\%). Foram constatados ainda 20\% de participação no Conselho Municipal dos Direitos da Pessoa com Deficiência. Desse modo, identificamos, nessas atividades, um importante indicador do compromisso ético-político assumido pelo assistente social na defesa da esfera pública e da consequente democratização dos serviços prestados à população usuária pela via do controle social.

Sob outro ângulo, porém, os dados sobre a participação/organização política dos assistentes sociais provenientes dos relatórios de visita da Cofi/SE em 2008 trazem preocupações que precisam ser enfatizadas. No que se refere ao envolvimento com as atividades do Cress/SE, os dados mostraram-se com uma leve vantagem para os profissionais que disseram não participar das atividades dessa importante entidade profissional $(53,8 \%)$. Entre os que participam, 50\% restringem essa participação às atividades da "semana do assistente social”, tradicionalmente organizada, pelos Cress's de todo o país. Sobre sua vinculação a alguma entidade organizativa aparece um dado ainda mais preocupante: os assistentes sociais visitados não percebem o Cress enquanto entidade organizativa. Isto significa afirmar que quando perguntados sobre vinculação com alguma entidade organizativa, o Cress não foi sequer mencionado nas respostas dos profissionais, sendo que $8,3 \%$ dos que declararam ter vinculação a alguma entidade organizativa identificaram apenas o Sepuma (Sindicato dos Servidores Públicos Municipais). O restante dos profissionais respondeu não estar vinculado a entidades organizativas, dado que pode ser visualizado no gráfico a seguir.

Essa questão é preocupante por duas razões. Primeiro pelo fato de que o conjunto CFESS/Cress vem se constituindo como uma importante referência na organização política dos assistentes sociais, desde o redirecionamento de sua dinâmica de trabalho em consonância com o debate profissional dos últimos trinta anos, conforme já mencionado (item 1). Deste modo, pergunta-se: como será que os assistentes sociais percebem o Cress, já que não o referenciam como entidade organizativa? Este dado fica a reclamar posteriores aprofundamentos na realidade do estado de Sergipe, por parte dos diferentes sujeitos envolvidos neste debate, mas principalmente, pela gestão do Cress-SE, podendo constituir-se num "alerta” aos demais Cress's. 


\section{Gráfico 2}

Vinculação a alguma entidade organizativa

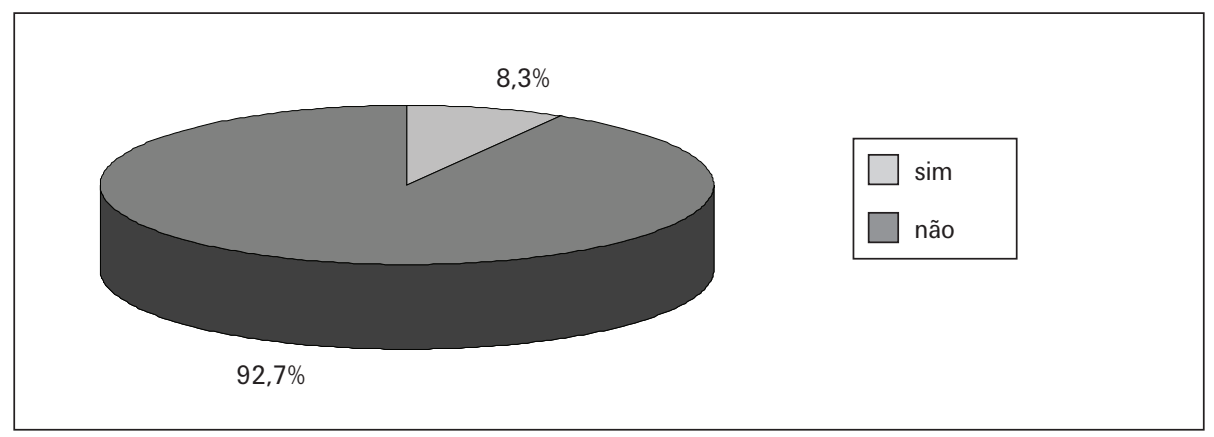

A outra razão das preocupações que este dado revela relaciona-se à fragilidade da participação sindical dos assistentes sociais, num momento em que observamos um movimento de retomada dos sindicatos da categoria dos assistentes sociais. Dessa forma, é importante lembrar que a maioria dos sindicatos dos assistentes sociais foi extinta quando a categoria decidiu se organizar em seções sindicais por ramo de atividade como estratégia política de somarem-se à luta aos demais trabalhadores ligados à sua área de atuação. Pensamos que a discussão do retorno ao sindicato dos assistentes sociais revela rastros de uma postura neoconservadora dentro do Serviço Social, colocando em xeque a hegemonia do projeto ético-político da profissão, conforme analisa Braz (2007, p. 7):

Aqui o projeto profissional corre sério risco. Outras expressões políticas da profissão - de variados tons neoconservadores — mais ou menos organizadas podem ganhar espaço e terreno em meio à degradação das condições de trabalho profissional. Podem se tornar atraentes os segmentos mais corporativistas da categoria que se evidenciam, não exclusivamente, em algumas associações sindicais dos assistentes sociais [...] que pululam no Serviço Social.

O próximo item analisado se refere à opinião sobre o Cress. É importante explicar que, segundo os dados coletados, tudo indica que essa pergunta levou a dois tipos de entendimento pelos profissionais visitados pela fiscalização: uma parte deles elabora, de fato, opiniões a respeito do Cress, e outra parte, em vez 
de formular opiniões, citou algumas ações desenvolvidas pela entidade. Houve ainda quem fizesse ambas as coisas ao mesmo tempo. Quando os profissionais foram questionados acerca da opinião que tinham sobre o Cress, $30 \%$ não respondera e o restante do percentual (70\%) evidenciou respostas que se dividiram entre emitir opiniões e/ou citar ações realizadas pelo Cress. No que diz respeito aos assistentes sociais que formularam opiniões acerca da entidade, vale dizer que $60 \%$ emitiram opiniões positivas a respeito da entidade e os outros $40 \%$ evidenciaram opiniões positivas com ressalvas.

No gráfico abaixo relacionamos as ações que foram citadas pelos assistentes sociais, enquanto atividades do Cress. ${ }^{13}$

\section{Gráfico 3}

Ações do Cress

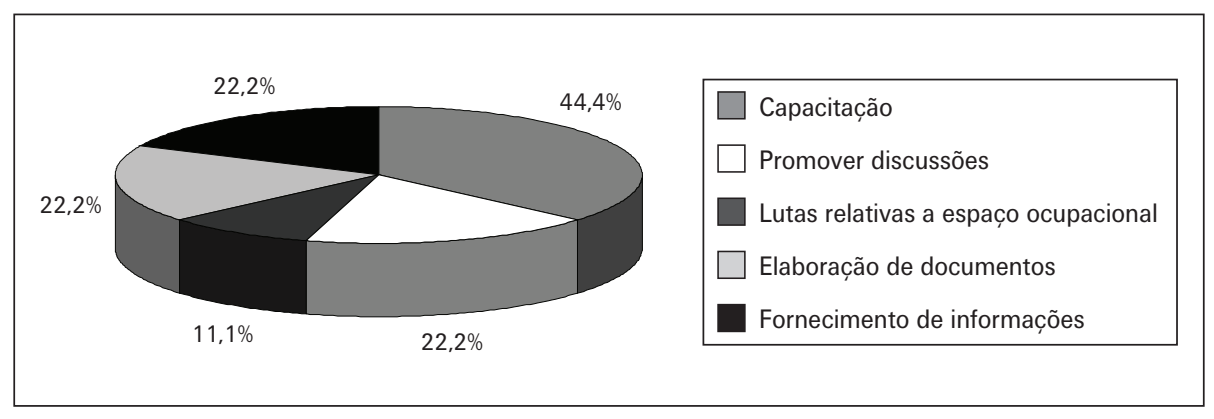

A maioria dos profissionais $(44,4 \%)$ relatou que o Cress realiza ações no campo da capacitação profissional. Isso provavelmente está relacionado com o fato de a formação continuada ser uma ação que perpassa dimensão político-pedagógica da PNF, o que tem levado o conjunto CFESS/Cress a dar prioridade à qualificação do exercício profissional por meio de uma "política de capacitação continuada", que se materializa em ações como a do curso de Especialização à Distância — organizado, atualmente na sua segunda versão, pelo CFESS - e o Curso Ética em Movimento.

13. É relevante explicar que os percentuais acima apresentados ultrapassam o valor de $100 \%$ por ter sido detectado que uma mesma pessoa citou mais de uma ação do conselho. 
Além disso, a atual formulação ética vigente no Serviço Social possui, entre seus princípios fundamentais, o "compromisso com o aprimoramento intelectual, na perspectiva da competência profissional". Esse princípio se materializa tanto na formação como no exercício profissional. É uma das características presentes na profissão desde o currículo mínimo de 1982, “alçada [...] ao patamar de dimensão constitutiva tanto da formação quanto do exercício profissional" (Almeida, 2000, p. 10). O novo projeto de formação profissional, materializado nas Diretrizes Gerais para o curso de Serviço Social de 1996, mantém, assim, "a dimensão investigativa como um dos [seus] componentes centrais" (Idem, p. 22).

O Serviço Social é uma profissão que está articulada conjuntural e estruturalmente à forma de organização social capitalista. Inscrita na divisão sociotécnica do trabalho, sua atuação ocorre, como já foi dito, no âmbito das políticas sociais, no enfrentamento das expressões da "questão social". "Trata-se de uma atuação essencialmente interventiva, porém conectada ao conhecimento da realidade na qual trabalha" (Pontes, 2000, p. 43). Desse modo, a relação entre a realidade e a profissão ocorre incessantemente, pois a premissa é marcada por transformações contínuas. Portanto, sua compreensão e enfrentamento numa perspectiva crítica dependem não somente da fundamentação teórico-metodológica e técnico-operativa. É preciso assumir uma postura investigativa, tomando sempre como referência o projeto ético-político da profissão.

O processo de investigação, tanto do objeto de trabalho, como das suas determinações histórico-estruturais, pressupõe uma formação constantemente atualizada, o que torna a qualificação profissional, portanto, um elemento fundamental para um trabalho comprometido, não somente com os princípios e compromissos éticos da profissão, mas também com as exigências da sociedade em geral. Ela possibilita que o trabalho profissional extrapole o planejamento e a execução de políticas sociais e adentre em espaços de democratização dessas políticas, que viabilizam o alargamento das funções e a potencialização dos princípios defendidos. Tal postura das entidades tem sido muito importante para a categoria, não só pelo fato de oferecer uma formação continuada, mas por representar um posicionamento político de compromisso para sintonizar a profissão com as novas configurações da "questão social", que, inseridas num 
contexto histórico adverso, reflete nas atribuições profissionais ao redimensionar os espaços sócio-ocupacionais e as demandas profissionais, fazendo com que o assistente social assuma novas competências diante dessa conjuntura. Sobre essa discussão, Iamamoto (2002, p. 19) considera que:

Os espaços ocupacionais e as fronteiras profissionais, enquanto resultantes históricos — e, portanto móveis e transitórias — sofrem significativas alterações. [...] Pensar o projeto profissional supõe articular [...] de um lado, as condições macrossocietárias que estabelecem o terreno sócio-histórico em que se exerce a profissão, seus limites e possibilidades; e, de outro lado, as respostas técnico-profissionais e ético-políticas dos agentes profissionais nesse contexto, que traduzem como esses limites e possibilidades são analisados, apropriados e projetados pelos assistentes sociais.

Ainda no tocante ao conteúdo do gráfico que expõe as ações citadas pelos profissionais visitados, observa-se que as atividades relacionadas à promoção de discussões, elaboração de documentos e fornecimento de informações aparecem com percentual empatado $(22,2 \%)$, seguidos de $11,1 \%$ dos profissionais que citaram como ações do Cress as lutas relativas à conquista de espaço sócio-ocupacional. Entre esses dados notamos, porém, que os profissionais não mencionaram a ação fiscalizatória do Cress, o que parece indicar a baixa visibilidade — junto aos profissionais de Sergipe — da fiscalização como atividade principal do Cress. Esse dado é bastante preocupante, tendo em vista a centralidade da fiscalização em virtude do caráter liberal da profissão, mas também da perspectiva que reflete (para além dos limites normativos) o compromisso ético-político com o projeto profissional da categoria.

\section{Consideraç̃es finais}

A discussão do trabalho profissional sob a ótica da sua fiscalização ainda é um tema pouco explorado na produção bibliográfica do Serviço Social. Considerando-se a natureza das profissões regulamentadas como liberais, os conselhos têm na fiscalização do exercício desses profissionais a sua razão de existir. No caso do Serviço Social, além dessa centralidade, o atualmente 
conhecido conjunto CFESS/Cress tem na PNF um decisivo instrumento para a propagação do projeto ético-político profissional. Nela temos clareza de que a defesa da profissão e sua imagem socialmente reconhecida passa por múltiplos condutos da vida social que nada têm a ver com a defesa corporativa dos espaços ocupacionais por questões de "reserva de mercado". A defesa da profissão tem a ver com a competência teórica e ético-política capaz de maximizar a luta pela superação das desigualdades tendo como mediações os direitos sociais numa perspectiva democrática e de universalidade. Isso pode, inclusive, levar a ações dos conselhos contra os profissionais considerados individualmente, em nome do projeto profissional coletivamente construído e suas balizas éticas e normativas.

No interior dessa concepção de fiscalização, a defesa das políticas públicas como estratégia de consolidação do projeto profissional ocorre em face do quadro configurado na década de 1990, marcado pela implementação do projeto neoliberal. Este trata, no âmbito do Estado, de medidas de reestruturação do capitalismo, com vistas à recuperação da lucratividade, com uma política econômica que se sobrepõe às políticas de proteção social, relegando a último plano as contrapartidas sociais e tornando-as mínimas. É esse quadro de flexibilização do trabalho, da produção e do consumo, assim como de reconfiguração dos espaços ocupacionais, que submete o exercício profissional a um processo de desregulamentação e de reconfiguração do seu perfil (Iamamoto, 2002). Esse contexto exige das entidades organizativas da categoria alternativas e caminhos de afirmação dos princípios e compromissos do projeto ético-político profissional do Serviço Social em defesa de determinada perspectiva para o exercício profissional. Por isso a fiscalização passa a incluir a luta pela democratização das políticas sociais públicas como forma de enfrentamento das condições adversas ao exercício profissional e, consequentemente, a defesa da universalização do acesso a bens e serviços por parte dos usuários, que compõe o que há de mais significativo nas condições de trabalho do assistente social.

Entre as iniciativas do conjunto CFESS/Cress para fiscalização e defesa do exercício profissional mediante uma concepção ampliada, de cunho educativo e politizado, estão inseridas várias atividades que perpassam o debate das condições de trabalho, mas também da capacitação profissional e da organização política da categoria. 
Neste sentido, os resultados preliminares dessa pesquisa, tendo como fonte os relatórios de visita da fiscalização feita pelo Cress no estado de Sergipe, constituem material de grande relevância, tanto para a formação quanto para o trabalho profissional. Sua sistematização possibilita captar como a PNF está sendo operacionalizada pelo Cress $18^{\mathrm{a}}$ Região, na perspectiva de contribuir com um mapeamento de situações que se revelam preocupantes, como a baixa visibilidade da fiscalização enquanto atividade do Cress por parte dos assistentes sociais ou a sua dificuldade em identificá-la como entidade organizativa. Por outro lado, permite-nos visualizar a consolidação da intervenção da categoria na dinâmica do controle social - tomada com destaque entre as atividades desenvolvidas pelos assistentes sociais fiscalizados em 2008, em Sergipe -, o que revela a capilaridade dos princípios ético-políticos na dinâmica do trabalho profissional, sintonizado com o debate e os esforços do conjunto CFESS/Cress.

Artigo recebido em jun./2009 - Aprovado em dez./2009

\section{Referências bibliográficas}

ALMEIDA, N. L. de. Desafios contemporâneos para a formação profissional em Serviço Social. O Social em Questão, Rio de Janeiro, v. 5. n. 5, p. 7-24, 2000.

ARANHA, M. L. M. Trabalho e mercado de trabalho do assistente social em Aracaju/ $S E$, nos últimos quatro anos. Projeto de pesquisa apresentado ao Pibic/CNPq/UFS. São Cristóvão, 2005. Mimeo.

BARROCO, M. L. S. Ética e Serviço Social: fundamentos ontológicos. São Paulo: Cortez, 2001.

BEHRING, E. R.; BOSCHETTI, I. Política social: fundamentos e história. 2. ed. São Paulo: Cortez, 2007.

BRASIL. Lei n. 8.662/93, de 7 de junho de 1993. Dispõe sobre a profissão de Assistente Social e dá outras providências. In: Assistente social: ética e direitos — Coletânea de leis e resoluções. Cress $7^{a}$ Região. Rio de Janeiro, 2002.

BRAZ, M. A hegemonia em xeque. O projeto ético-político do Serviço Social e seus elementos constitutivos. Revista Inscrita, Brasília, n. X, ano VII, 2007. 
CFESS. Serviço social a caminho do século XXI: o protagonismo ético-político do conjunto CFESS/CRESS. Serviço Social \& Sociedade, São Paulo, n. 50, 1996.

(Org.). Assistentes sociais no Brasil: elementos para o estudo do perfil profissional. Brasília: CFESS, 2005.

. Código de Ética do Assistente Social. Resolução Cfess n. 273/93, Brasília, 1997.

Política Nacional de Fiscalização. In: Instrumentos para a fiscalização do exercício profissional do assistente social. Brasília: CFESS, 2007.

O CFESS e os desafios político-profissionais do Serviço Social. Serviço Social \& Sociedade, São Paulo, n. 95, 2008.

COFI/CFESS. Reflexões sobre as atribuições privativas do(a) assistente social. Atribuições privativas do(a) assistente social em questão. Brasília: CFESS, 2002.

IAMAMOTO, M. V. Projeto profissional, espaços ocupacionais e trabalho do assistente social na atualidade. In: CFESS. Atribuições privativas do(a) assistente social em questão. Brasília: CFESS, 2002.

; CARVALHO, R. de. Relações sociais e Serviço Social no Brasil: esboço de uma interpretação histórico-metodológica. 10. ed. São Paulo: Cortez, 2007.

JESUS, E. A. Trabalho e mercado de trabalho do assistente social em Aracaju/SE, nos últimos quatro anos (setor público). Relatório semestral de projeto de pesquisa. Sergipe: Pibic/CNPq/UFS, 2006.

NETTO, J. P. Ditadura e Serviço Social: uma análise do Serviço Social no Brasil pós-64. 2. ed. São Paulo: Cortez, 2007.

A construção do projeto ético-político do Serviço Social frente à crise contemporânea. In: UnB. Capacitação em Serviço Social e política social: Módulo 1 - Crise contemporânea, questão social e Serviço Social. Brasília: Cead, 1999.

2001.

Capitalismo monopolista e Serviço Social. 3. ed. ampl. São Paulo: Cortez,

PONTES, R. N. Mediação: categoria fundamental para o trabalho do assistente social.

In: Capacitação em Serviço Social e política social: Módulo 4. Brasília: Cead/CFESS/ UnB, 2000. p, 34-49.

RAICHELIS, R. Democratizar a gestão das políticas sociais - um desafio a ser enfrentado pela sociedade civil. In: MOTA, Ana Elizabeth et al. (Orgs.). Serviço Social e saúde. 2. ed. São Paulo: Opas, OMS, Ministério da Saúde, 2007. 
SANTOS, D. R. Trabalho e mercado de trabalho do assistente social em Aracaju/SE, nos últimos quatro anos (setor empresarial). Relatório semestral de projeto de pesquisa. Sergipe: Pibic/CNPq/UFS, 2005a.

Trabalho e mercado de trabalho do assistente social em Aracaju/SE, nos últimos quatro anos (Organizações Não Governamentais). Relatório semestral de projeto de pesquisa. Sergipe: Pibic/CNPq/UFS, 2005 b.

SANTOS, J. S. O perfil do exercício profissional do assistente social sob a ótica da sua fiscalização pelo Cress $18^{a}$ Região/SE no período 2002-2008. Projeto de pesquisa. São Cristovão: UFS, Pibic/CNPq, 2008.

SETÚBAL, A. A. Introdução. In: Pesquisa em Serviço Social: utopia e realidade. 3. ed. São Paulo: Cortez, 2005.

SILVEIRA, J. I. Política Nacional de Fiscalização: a centralidade da dimensão político-pedagógica. In: CFESS. Instrumentos para a fiscalização do exercício profissional do assistente social. Brasília, 2007.

TERRA, S. H. Atribuições privativas e regulamentação do exercício profissional. In: CFESS. Instrumentos para a fiscalização do exercício profissional do assistente social. Brasília, 2007. 